\title{
Blocking Episodes in the Southern Hemisphere: Impact on the Climate of Adjacent Continental Areas
}

\author{
Monica Cristina Damião Mendes, ${ }^{1}$ Ricardo Machado Trigo, ${ }^{1,2}$ \\ Iracema F. A. Cavalcanti, ${ }^{3}$ and Carlos. C. DaCamara ${ }^{1}$
}

\begin{abstract}
This work presents an updated climatology of blocking episodes for the Southern Hemisphere between 1960 and 2000, based on data from NCEP/NCAR reanalysis. Five contiguous areas of blocking activity are considered; Southeastern Pacific, Southwestern Pacific, Atlantic, Indian and Oceania. The impact of the three most important areas of onset blocking episodes (Southeastern Pacific, Atlantic and Oceania) upon the climate of the adjacent continental areas (South America and Australia) was evaluated. Composites of the meteorological variables (temperature and precipitation) were obtained for periods of diagnosed blockings. The impact of the blocking episodes over the climate of South America and Australia is highlighted whenever anomaly fields of temperature and precipitation are significant at the 5\% and $10 \%$ levels, respectively. Impacts of Southeastern Pacific and Atlantic blockings are observed on the temperature field over several regions of South America. Significantly higher (lower) temperatures than climatology occur in southern Brazil, northern Argentina, Uruguay and Paraguay, and lower (higher) than climatology in the extreme south of South America for the Southeastern Pacific (Atlantic) blocking episodes. Precipitation over South America is also affected by the Southeastern Pacific and Atlantic blockings in different ways. The Southeastern Pacific blocking has higher impact on precipitation in summer (dry conditions in northeast Brazil) and spring (wet conditions in central and southern Brazil), while the Atlantic blocking affects precipitation in autumn and winter (wet conditions in parts of central and southern Brazil). The blocking cases over Oceania affect southeastern Australia with normal to higher than climatological precipitation and with negative temperature anomalies in that region. Finally we provide a detailed analysis of a South Atlantic blocking episode, which occurred between the $4^{\text {th }}$ and the $8^{\text {th }}$ of June 1997 . This event shows clearly the split of the jet stream into two branches (subtropical and polar) surrounding the anticyclonic sector, and satellite imagery revealed the presence of transient systems in the periphery of the blocking anticyclone responsible for high values of precipitation in the southeastern sector of South America.
\end{abstract}

Key words: Blocking, Southern Hemisphere, South America, Australia, climate impacts, temperature, precipitation.

\section{Introduction}

Blocking episodes in the Southern Hemisphere $(\mathrm{SH})$ are characterized by well developed and persistent ridges centered at $50^{\circ}-65^{\circ} \mathrm{S}$ latitudes, i.e., poleward of the

\footnotetext{
${ }^{1}$ CGUL, IDL, University of Lisbon, Lisbon, Portugal. E-mail: rmtrigo@fc.ul.pt

2 Departamento de Engenharias da Universidade Lusófona, Lisbon, Portugal.

3 Centro de Previsão de Tempo e Estudos Climáticos, INPE, São Paulo, Brazil.
} 
subtropical highs. These systems are important because they induce steady atmospheric conditions underneath and large meridional displacements of synoptic scale transient eddies (Sinclair, 1996; WiedENMANn et al., 2002; RENwick, 2005). The number of studies addressing the impact of blocking episodes on the climate of adjacent areas is considerably higher for its Northern Hemisphere than for its Southern counterpart. Pioneering research for the European sector has shown that the occurrence of just a few blocking episodes per season, over a particular region, may be important enough to induce a climate effect underneath and in adjacent areas, causing seasonal anomalies in temperature and precipitation (REX, 1950a, 1950b, 1951). These results have been checked for robustness using more variables and a considerably longer data set (TRIGO et al., 2004). Weather impacts downstream of atmospheric blocking patterns also have been described for the Northeast Pacific sector (CARRERA et al., 2004). These results confirm the relevance of blocking episodes to induce adverse prolonged atmospheric conditions over North America, namely drought episodes under the anticyclonic region and floods in both the equatorial and polar flanks (KNOX and HAY, 1984).

In recent years, a growing number of studies have been developed with the aim of providing blocking climatologies for the entire $\mathrm{SH}$, or for specific sectors of the $\mathrm{SH}$. Due to their relevance to this work, a summary of these studies is given in Table 1. It is possible to infer that until the end of the 1990s the vast majority of these works used relatively short periods $(<25 \mathrm{yr})$ to build up and then characterize blocking patterns. More recently, the availability of extensive reanalysis data sets has allowed longer studies. Nevertheless, only six out of seventeen papers employ time series with periods of $30 \mathrm{yrs}$ or more. From the methodological point of view most of these analyses have used blocking definition algorithms based on either a) geopotential height gradients (Lejenas, 1984; Tibaldi et al., 1994; Marques, 1996; Marques and Rao, 2001; Wiedenmann et al., 2002; Adana and Colluci, 2005), and b) persistent positive anomalies of pressure (Trenberth and Mo, 1985; Ruthland and Fuenzelida, 1991; Sinclair, 1996; Renwick, 1998, 2005; Renwinck and Revell, 1999; Montecinos and Aceituno, 2003; DAmião et al., 2005). A few papers have used less common blocking definition techniques, e.g., Empirical Orthogonal Functions (KAYANO, 1999; RAPHAEL, 2003).

Previous works dealing with the whole SH (LejenAs, 1984; Trenberth and Mo, 1985; Kayano and Kousky, 1990; Ruthland and Fuenzelida, 1991) agree on the predominance of blocking episodes over the Australian-New Zealand sector, followed by the Southeastern Pacific, a considerably less number of episodes occurring over the Southern Atlantic and the Indian Ocean. These works have also considered the Pacific Ocean as a single sector, whereas following the work of SincLAIR (1996) and RENwICK and REvelL (1999), authors started considering a partition of the Southern-Pacific Ocean into the southwestern and the southeastern sectors.

Previous studies have focused on blocking climatologies and most of them do not address the impact of the blocking patterns on the climate of adjacent areas (see Table 1). The four studies that assess climate impacts are restricted to the South American continent. 


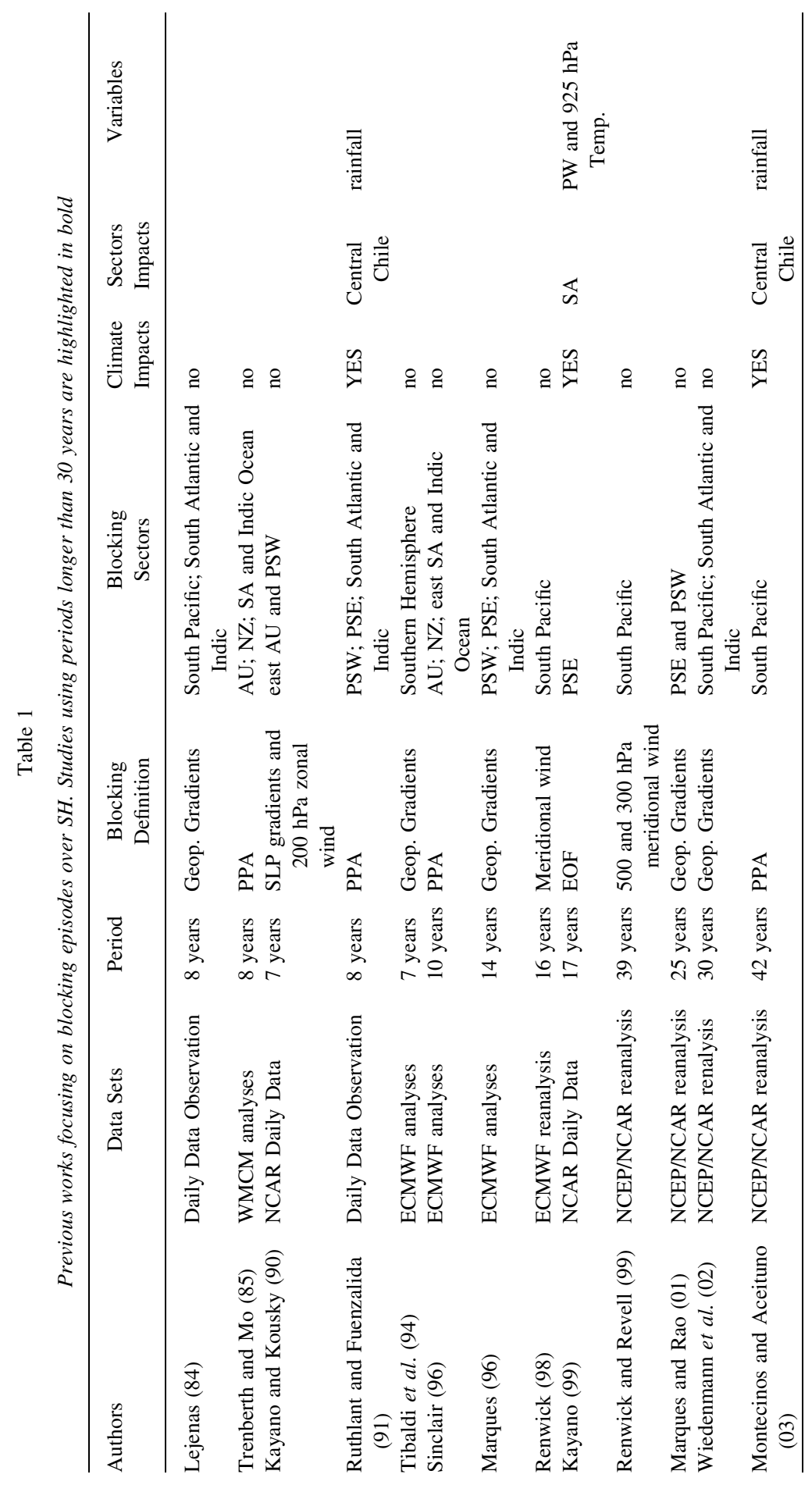




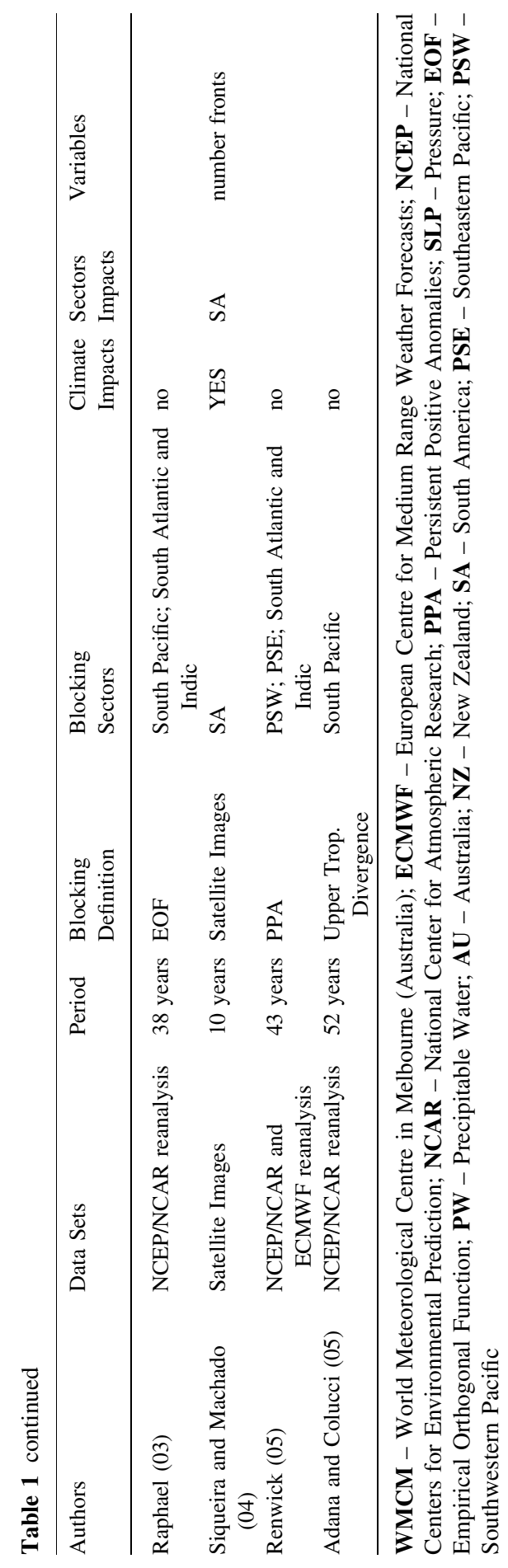




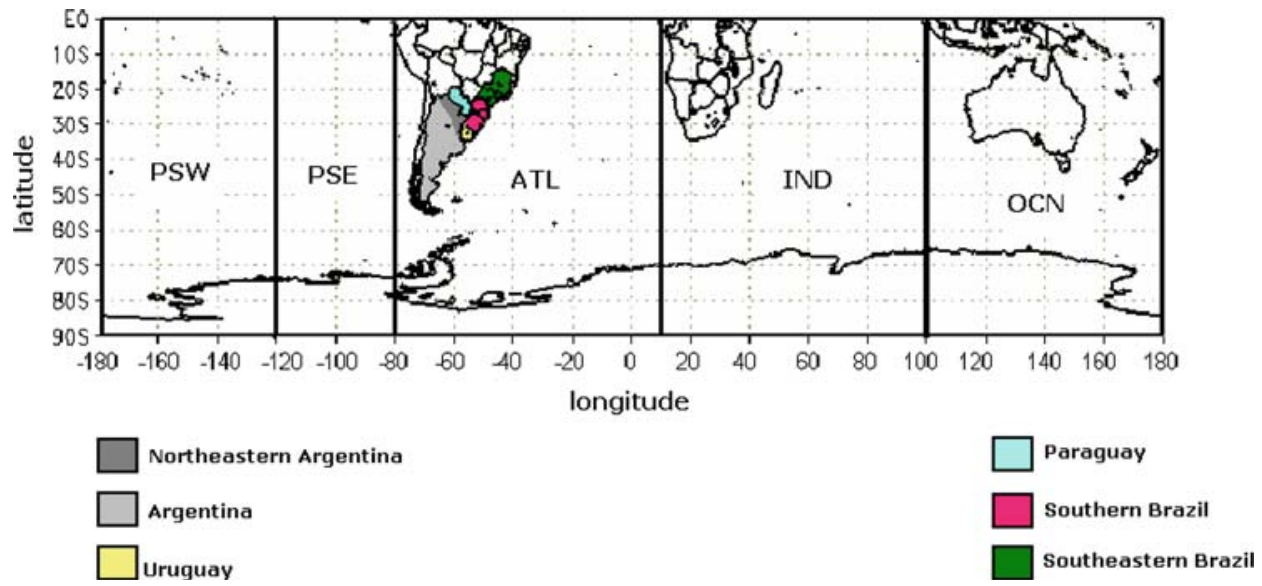

Figure 1

Longitudinal distribution of the five selected areas; Southwestern Pacific (PSW), Southeastern Pacific (PSE), Southern Atlantic (ATL), Indian (IND) and Oceania (OCN).

Therefore, we believe there is scope for performing a long-term climatological analysis of blocking episodes for the whole SH and, simultaneously, evaluating the impact of blocking patterns on the climate of nearby regions.

The main objectives of this work are two fold:

a) to develop a comprehensive 41-yr blocking climatology for the $\mathrm{SH}$ using the circulation indices introduced by TiBALDI and MoLTENI (1990) and TiBALDi et al. (1994) for the $\mathrm{NH}$,

b) to assess the climate impact of blocking episodes over continental areas with particular attention to South America and Australia.

Data and the criteria to define blocking episodes are introduced in Section 2. Section 3 describes the main characteristics of the SH blocking areas and their climate impact on the adjacent continental areas. Section 4 describes in more detail a blocking episode that was associated with a long drought in the central sector of South America. Finally, the conclusions are presented in section 5.

\section{Data and Methodology}

\subsection{Data}

The main data set used in this study is a daily gridded time series for the 1960-2000 period as retrieved from the National Centers for Environmental Prediction-National Center for Atmospheric Research (NCEP-NCAR) Reanalysis. The following set of variables was extracted for the entire Southern Hemisphere, with a $2.5^{\circ}$ latitude by $2.5^{\circ}$ 
longitude grid resolution: Sea level pressure (SLP), $500 \mathrm{hPa}$ geopotential height, $850 \mathrm{hPa}$ temperature, zonal and meridional wind at $850 \mathrm{hPa}, 500 \mathrm{hPa}$ and $200 \mathrm{hPa}$ and vertical velocity (omega) between $1000 \mathrm{hPa}$ and $300 \mathrm{hPa}$. Surface variables, namely precipitation and maximum $\left(\mathrm{T}_{\max }\right)$ and minimum $\left(\mathrm{T}_{\min }\right)$ temperatures, were also extracted from NCEP/NCAR reanalysis with the available resolution of $1.875^{\circ}$ latitude by $1.875^{\circ}$ longitude. Daily mean temperature was calculated by simple averaging $T_{\max }$ and $T_{\min }$.

The NCEP/NCAR reanalysis data were derived from a consistent assimilation and modeling procedure that incorporated all the available observed conditions obtained from conventional and satellite information (KALnAy et al., 1996). While the assimilation system has been frozen throughout the whole reanalysis process, the observation base has undergone significant changes over the considered period (WHITE, 2000). Moreover, the quality of reanalysis data sets is also dependent upon the skill and reliability of the forecast model employed. While variables such as SLP, $500 \mathrm{hPa}$ geopotential height and $850 \mathrm{hPa}$ temperature belong to the set of observed variables that were analyzed by the model, precipitation is a member of the class of variables that depends upon the forecast model (Kalnay et al., 1996). However, it is convenient to bear in mind that most of the analyses presented in this work are based on the use of anomaly composites (average field removed), therefore filtering the impact of model inadequacies on our results (TRIGO et al., 2002, 2004). In addition, surface climate variables from reanalysis have previously shown some skill in comparison with observations for the Northern (e.g., WIDMANN and Bretherton, 2000; Stendel and Arpe, 1997) and Southern (e.g., Rao et al., 2002) Hemispheres. Finally, we have also used remote-sensed imagery from the satellite GOES- 8 corresponding to the 5 -day period between the $4^{\text {th }}$ and $8^{\text {th }}$ of June, 1997 which was characterized by a blocking event in the southern Atlantic sector. Satellite images were provided and pre-processed by Centro de Previsão de Estudos Climáticos/Instituto Nacional de Pesquisas Espaciais (CPTEC/INPE) in Brazil.

\subsection{Blocking Definition}

The set of blocking diagnostics compiled in this study consists of the number of episodes, duration and location. Here, our study has been carried out using the "standard" methodology developed by TiBALDi et al. (1994), and recently refined by TRIGo et al. (2004) for the NH. Therefore, two $500 \mathrm{hPa}$ geopotential height meridional gradients GHGS (south) and GHGN (north) are evaluated for $2.5^{\circ}$ longitude intervals over the entire SH:

$$
\begin{aligned}
& G H G S=Z\left(\lambda, \phi_{S}\right)-Z\left(\lambda, \phi_{02}\right), \\
& G H G N=Z\left(\lambda, \phi_{01}\right)-Z\left(\lambda, \phi_{N}\right),
\end{aligned}
$$

where:

$$
\begin{aligned}
& \phi_{N}=40^{\circ} S+\Delta \\
& \phi_{01}=55^{\circ} S+\Delta
\end{aligned}
$$




$$
\begin{aligned}
& \phi_{02}=50^{\circ} S+\Delta \\
& \phi_{S}=65^{\circ} S+\Delta \\
& \Delta=-10.0^{\circ},-7.5^{\circ},-5.0^{\circ},-2.5^{\circ}, 0^{\circ} .
\end{aligned}
$$

In the above expressions $Z(\lambda, \phi)$ is $500 \mathrm{hPa}$ height at latitude $\phi$ and longitude $\lambda$. Following the procedure developed by TiBALDI and Molteni (1990), a given longitude is defined as "blocked" at a specific instant in time if the following conditions are satisfied for at least one value of $\Delta$ :

$$
\begin{gathered}
\text { GHGN }>0, \\
\text { GHGS }<-10 \text { m. }
\end{gathered}
$$

A sector is considered to be blocked, on a particular day, if three or more adjacent longitudes within a pre-defined large area are blocked (TRIGO et al., 2004). This criterion is sufficient to define a local (in space) blocking pattern. However, a true synoptic blocking event requires a certain persistence in time. There is no minimum duration value for blocking episodes that is globally accepted. However, the typical duration of blocking episodes varies between 5 and 30 days in the SH (Treidl et al., 1981; Tibaldi and MoltenI, 1990). Here, we have adopted a threshold of five consecutive blocked days to the circulation constraints defined by equations (1) and (2) and criteria given by expressions (3) and (4). Finally, it may be noted that similar temporal criteria to ours have been adopted in operational centers such as NCEP (http://www.cpc.ncep.noaa.gov/ products/precip/CWlink/MJO/block.shtml) and that we have compared our results against those obtained by other authors for the Southern Hemisphere (LEJENAS, 1984; TibALDI et al., 1994; Marques, 1996; Marques and Rao, 2001; Wiedenman et al., 2002; Adana and Colluci, 2005).

The blocking episodes during the 41-year period (1960 to 2000) were identified by means of the above-defined rules (equations 1 and 2) over the following five contiguous sectors that cover the entire SH and are shown in Figure 1; (PSW) Southwestern Pacific $\left(180^{\circ} \mathrm{W}\right.$ to $\left.120^{\circ} \mathrm{W}\right)$, (PSE) Southeastern Pacific $\left(120^{\circ} \mathrm{W}\right.$ to $\left.80^{\circ} \mathrm{W}\right)$, (ATL) Southern Atlantic $\left(80^{\circ} \mathrm{W}\right.$ to $\left.10^{\circ} \mathrm{E}\right)$, (IND) Indian $\left(10^{\circ} \mathrm{E}\right.$ to $\left.100^{\circ} \mathrm{E}\right)$ and $(\mathrm{OCN})$ Oceania $\left(100^{\circ} \mathrm{E}\right.$ to $\left.180^{\circ} \mathrm{E}\right)$. It may be noted that these areas, which are in close agreement with those defined by other authors (MARQUES, 1996; SINCLAIR, 1996), were specifically designed to enclose distinct clusters of blocking episodes.

\subsection{Impact of Blocking Episodes}

The spatial extent of significant anomalies of precipitation and mean temperature at $2 \mathrm{~m}$ was computed by applying an appropriated statistical test ( $t$ statistic), to the null hypothesis of equal average, unilateral, with $t$ critical depending on the quantity of blocking episodes found in each sector and in each season of the year. With this approach we aimed to identify large coherent areas (particularly over the continents) that experienced unusual conditions due to the presence of blocking episodes. We have 
highlighted those regions where differences between composites and climatology are significant at the 5\% level (temperature) and the $10 \%$ level (precipitation). It is worth stressing that the evaluation of the degrees of freedom to estimate the significance of the $t$ statistic was based on the restrictive criterion adopted in HANSEN et al. (1993), i.e., taking only into account the number of blocking episodes (with at least 5 days), not the (considerably larger) number of blocked days.

\section{Results}

\subsection{Blocking Climatology}

The obtained relative frequency (\%) of blocked days, for each month per region, is given in Table 2. Overall, these results are in agreement with other authors that have used either similar (e.g., MARQues and RAO, 1999, 2000 and 2001) or different blocking definitions (e.g., Renwick and Revell, 1999). It is worth noting that the region of maximum blocking activity seems to be associated with the presence of maximum speed of the westerlies over the Southern Pacific (polar and subtropical jets) at high levels (Trenberth, 1984; Trenberth and Mo, 1985). Table 3 presents the number of identified blocking episodes for each one of the five contiguous sectors as a function of the respective duration in days. Over the Atlantic Ocean the majority of blocking events lasted 5 to 6 days and this duration was also found in the Indian Ocean, although with a reduced number of cases. In turn, over the southeastern and southwestern Pacific, and Oceania the blocking duration was typically from 6 to 9 days. Despite the different methodology and the longer period analyzed, obtained results present a good consistency with those published in a set of previous works as cited by WIEDENMANN et al. (2002),

Table 2

Relative frequency (\%) of blocked days for each month over the five defined sectors: Southwestern Pacific (PSW), Southeastern Pacific (PSE), South Atlantic (ATL), Indian (IND), and Oceania (OCN)

\begin{tabular}{lcclll}
\hline & PSW & PSE & ATL & IND & OCN \\
\hline JAN & 10 & 1 & 0 & 0 & 9 \\
FEB & 8 & 1 & 1 & 0 & 8 \\
MAR & 16 & 1 & 1 & 0 & 5 \\
APR & 14 & 4 & 3 & 0 & 9 \\
MAY & 22 & 10 & 6 & 1 & 14 \\
JUN & 20 & 14 & 4 & 1 & 19 \\
JUL & 27 & 12 & 4 & 0 & 25 \\
AUG & 26 & 10 & 3 & 0 & 20 \\
SEP & 20 & 7 & 6 & 0 & 10 \\
OCT & 12 & 2 & 5 & 0 & 4 \\
NOV & 9 & 2 & 1 & 1 & 8 \\
DEC & 14 & & & 1 & 12 \\
\hline
\end{tabular}




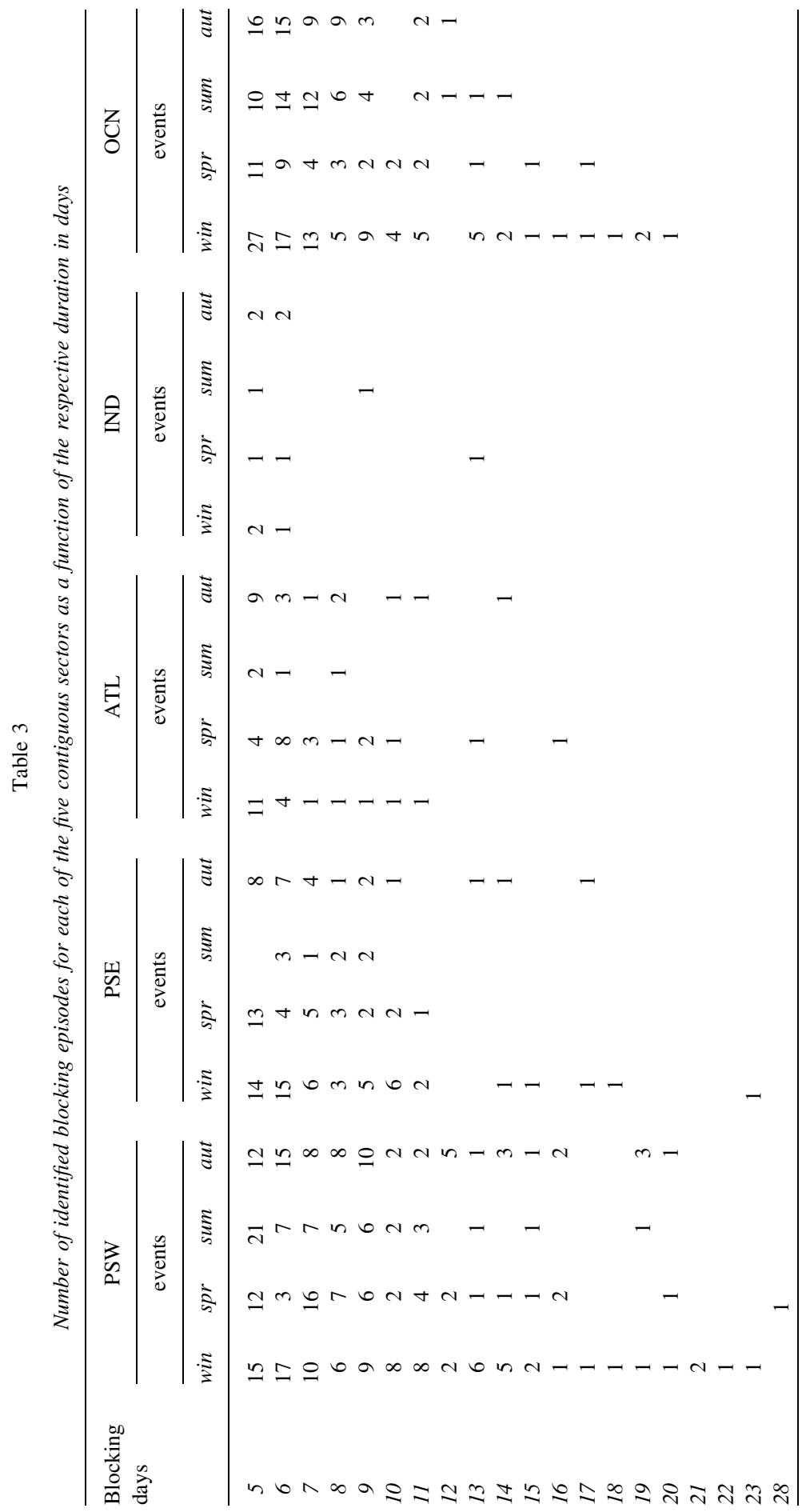


where the duration of blocking episodes ranges between 5 and 9 days. WIEDENMANN et al. (2002) also observed that the average duration of the blocking events for the South Pacific is 8 days, whereas for the South Atlantic and Indian Oceans the duration is between 5 and 7 days.

The frequency of blocking episodes presents a strong seasonal variability, with the greatest number of blocking episodes occurring in winter and the beginning of spring (from June to September). This result is coherent with those obtained by other authors, e.g. Marques and Rao (1999, 2000), Sinclair (1996) and Wiedenmann et al. (2002). The largest frequency of the blocking episodes during the months of June to September seems to be associated with the most intense meridional thermal gradient observed at this time of the year, and to the northward displacement of the polar and subtropical jets, the latter reaching its maximum intensity in winter and affecting South America (Climanálise, 1996). Conversely, during the summer months, when the blocking frequency declines over the Southern Pacific, the subtropical jet practically vanishes over South America, and the polar jet prevails at higher latitudes (PEzzI and Cavalcanti, 1994).

\subsection{Atmospheric Characteristics Associated with Blocking Episodes and Impacts}

Due to the robustness of their thermo-hydrodynamical structure, blocking episodes tend to prevent the normal progression of transient systems (e.g., cold fronts and extratropical cyclones), favoring adverse and persistent meteorological conditions over the nearby regions. Figures 2 to 5 present a set of composites of anomalous fields of geopotential height, streamlines of anomalous winds, temperature and precipitation. Composites respect to blocking episodes over PSE, ATL and OCN during the four seasons for the period 1960-2000. Anomalous fields of $500 \mathrm{hPa}$ geopotential height and $850 \mathrm{hPa}$ temperature (Fig. 2) reveal the coexistence of positive high centers with a warm core and negative ones with a cold nucleolus. These features are characteristic of equivalent barotropic structures that extend deep into the high troposphere and possess a coherent vertical structure that is well depicted in Figure 3, where the $850 \mathrm{hPa}$ and $200 \mathrm{hPa}$ geopotential height anomaly fields are super imposed. The same vertical coherence is also present in the streamlines of $850 \mathrm{hPa}$ and $200 \mathrm{hPa}$ anomalous winds that are shown in Figures 4 and 5, respectively.

It may be noted that the geopotential anomalies at high levels (Fig. 3) are less intense in the equatorial branch, extending zonally and favoring the transient systems path (storm tracks), in good agreement with previous results (e.g., TREnBERTh, 1986b). This hypothesis is reinforced by the presence of a band of negative $2 \mathrm{~m}$ temperature anomaly and positive anomaly precipitation as shown in Figures 4 and 5, respectively. It is worth stressing that the representation of anomalous temperature and precipitation fields was restricted to those regions where significant anomalies depart from climatology at the 5\% and $10 \%$ significance levels, respectively. In the three analyzed sectors, the areas with significant precipitation anomalies can be observed preferably over the oceans 


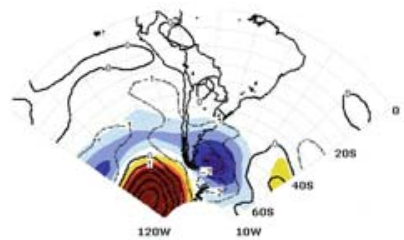

(a)

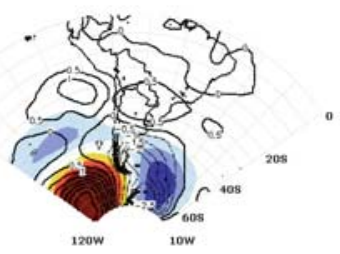

(b)

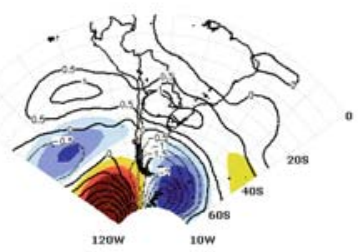

(c)

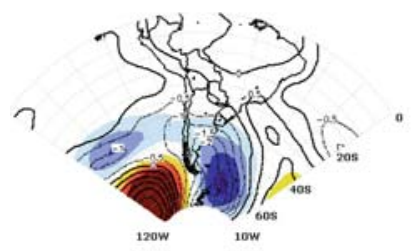

(d)

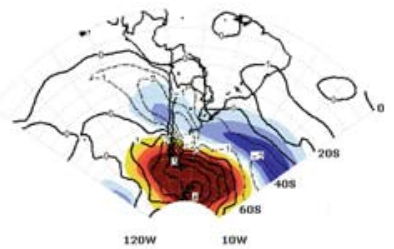

(e)

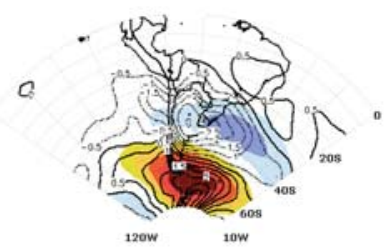

(f)

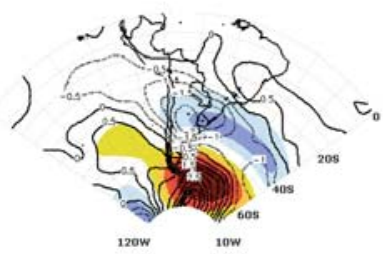

(g)

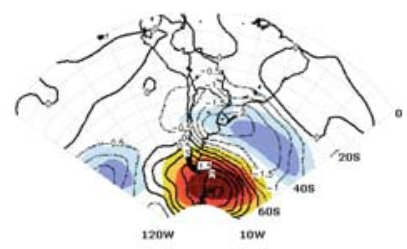

(h)

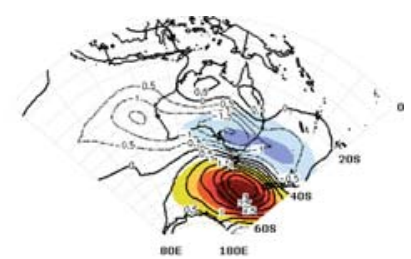

(i)

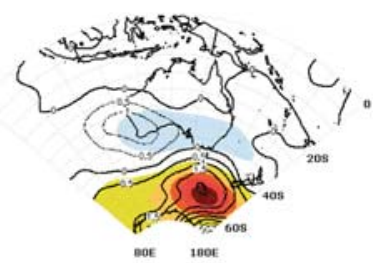

(j)

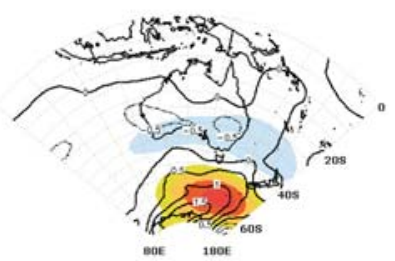

(k)

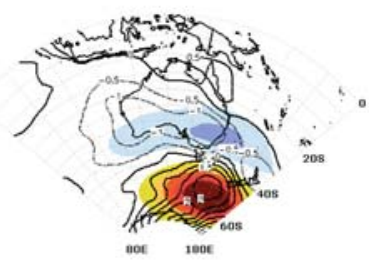

(1)

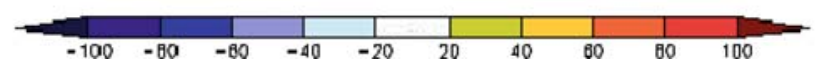

Figure 2

Composites of $500 \mathrm{hPa}$ geopotential height (shaded, mgp) and $850 \mathrm{hPa}$ temperature (contour, ${ }^{\circ} \mathbf{C}$ ) anomaly fields for blocking episodes in the (a, e, i) summer, (b, f, j) autumn, (c, g, k) winter, (d, h, l) spring, over (left panel) PSE, (central panel) ATL, and (rigth panel) OCN, for the 1960 to 2000 period.

(essentially in the equatorial part of the blocking pattern in a consistent way with the respective temperature fields).

In the case of PSE, the common features in the four seasons are the anomalous trough-ridge pair over the southeastern Pacific and the anomalous trough to the east. Negative temperature anomalies at $850 \mathrm{hPa}$ are observed over the extreme south of South 


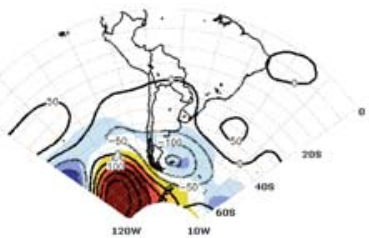

(a)

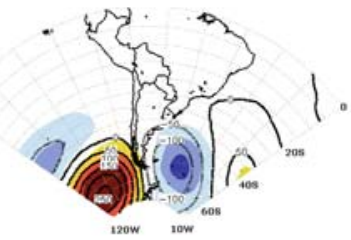

(b)

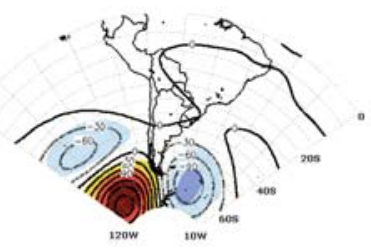

(c)

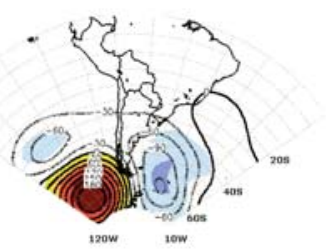

(d)

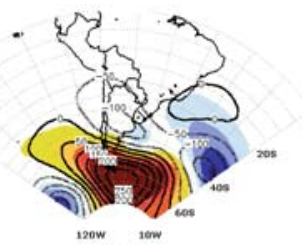

(e)

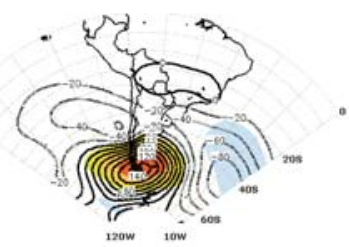

(f)

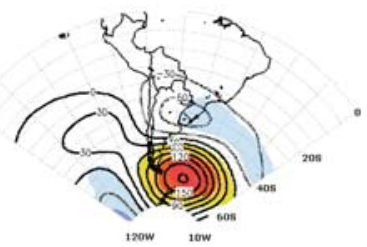

(g)

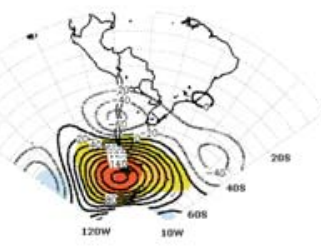

(h)

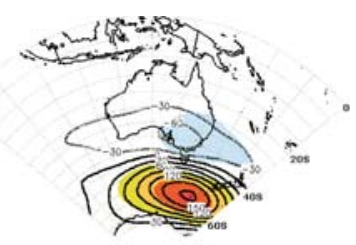

(i)

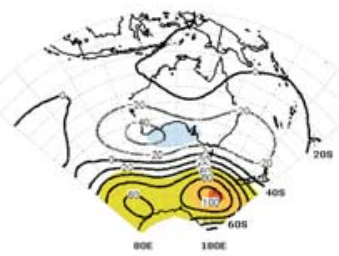

(j)

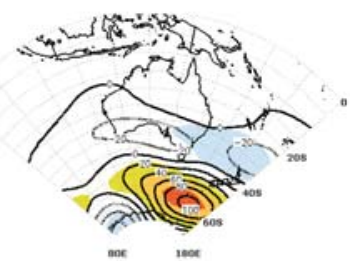

(k)

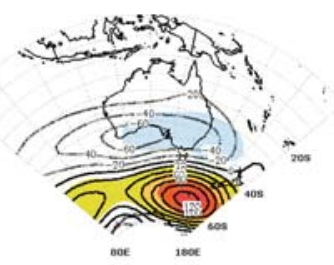

(1)

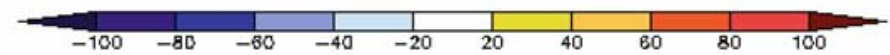

Figure 3

As in Figure 2 but with respect to composites of $850 \mathrm{hPa}$ (shaded, mgp) and $200 \mathrm{hPa}$ (contour, mgp) anomaly geopotential height fields.

America associated with the anomalous trough (Figs. 2a-d and Figs. 3a-d), that results from the influence of synoptic systems. The persistence of the trough and synoptic systems in that location reflects on the $2 \mathrm{~m}$ temperature (Figs. 4a-d) and precipitation (Figs. 5a-d). Colder than normal temperatures at $2 \mathrm{~m}$ are also seen in the extreme south of South America, where there is also above normal precipitation. Impacts on temperature of other regions of South America are identified in autumn and winter, with 


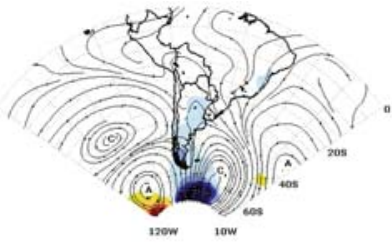

(a)

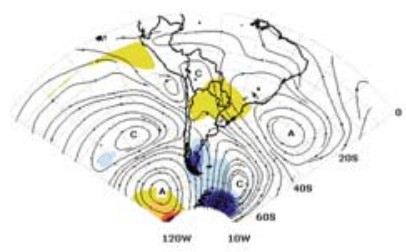

(b)

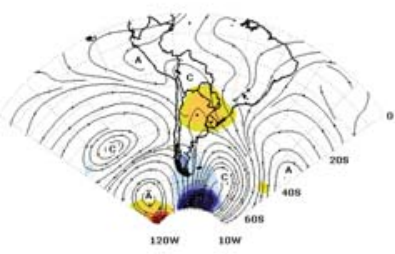

(c)

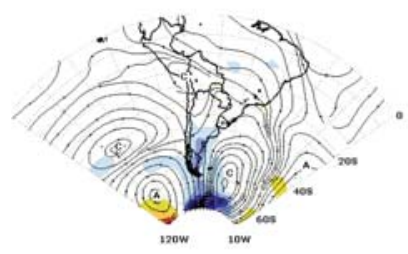

(d)

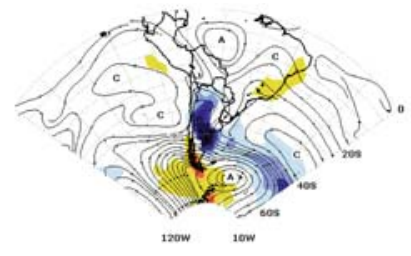

(e)

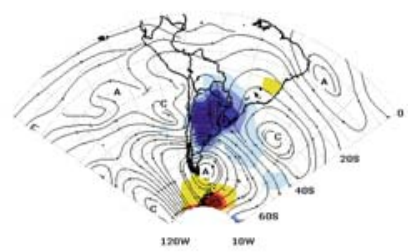

(f)

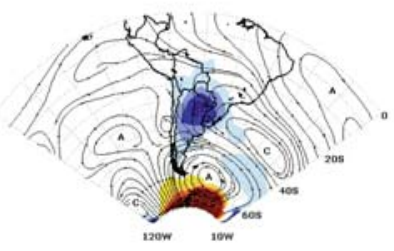

(g)

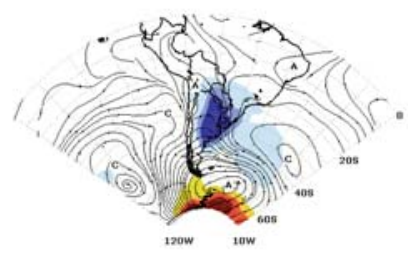

(h)

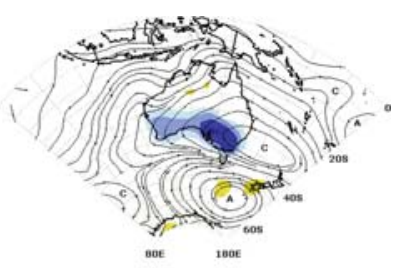

(i)

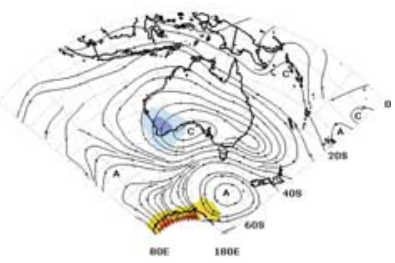

(j)

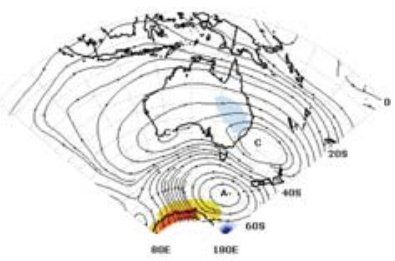

(k)

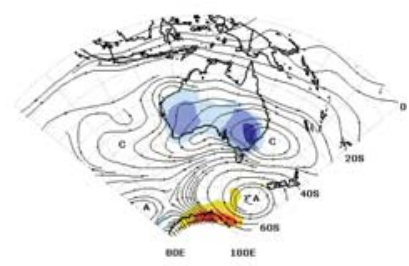

(I)

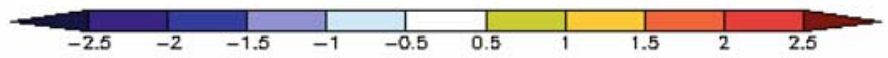

Figure 4

As in Figure 2 but with respect to composites of $2 \mathrm{~m}$ average temperature anomaly fields (shaded, $\mathbf{C}^{\circ}$ ) and $850 \mathrm{hPa}$ streamlines of anomalous wind $\left(\mathbf{m s}^{-\mathbf{1}}\right)$. Anomalous temperature fields are restricted to regions where departures from climatology are statistically significant at the 5\% level.

northern Argentina, Paraguay and southern Brazil (Figs. 4c, d) being affected by higher than normal temperature. The impact of blocking episodes on temperature over South America appears therefore to be more pronounced during the coldest months, with the exception of the extreme south of South America. The effects of blocking episodes on precipitation are also identified in other regions of South America, mainly in summer and 


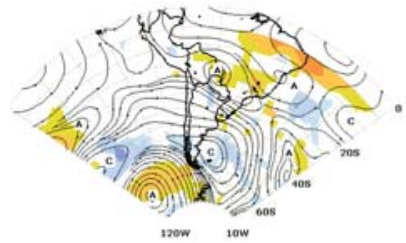

(a)

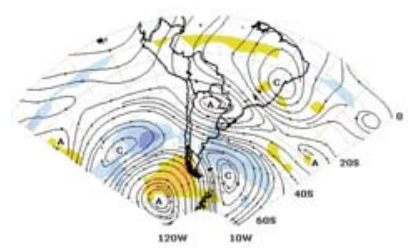

(b)

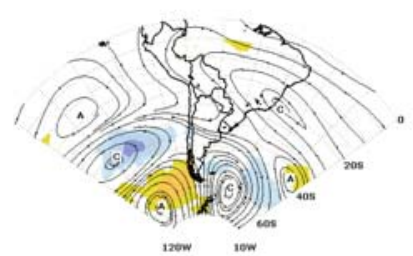

(c)

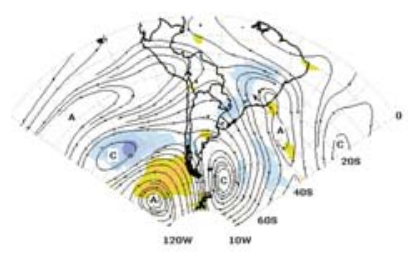

(d)

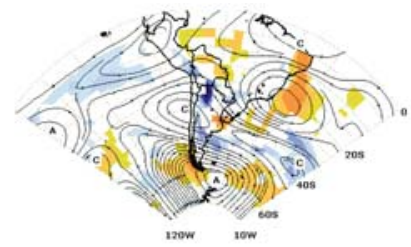

(e)

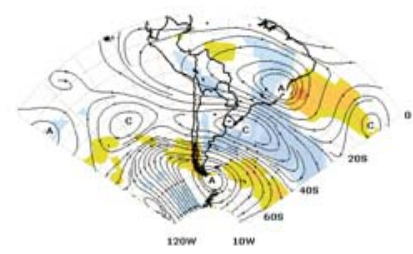

(f)

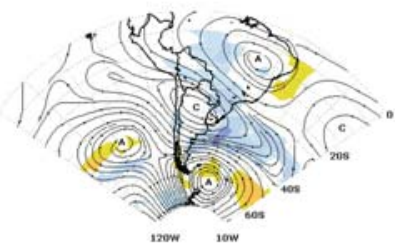

(g)

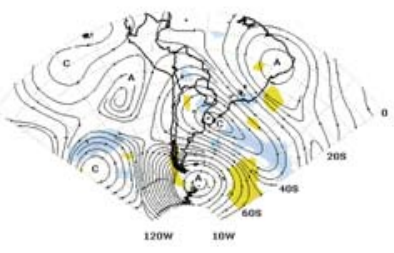

(h)

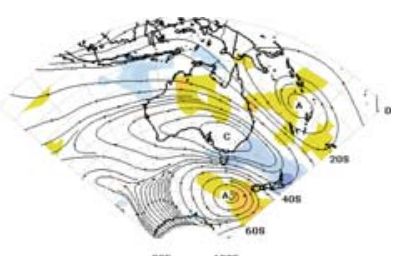

(i)

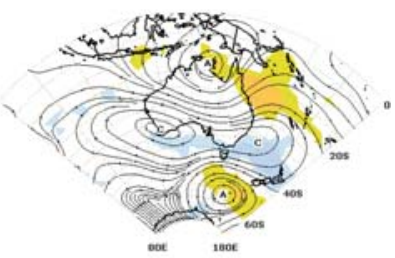

(j)

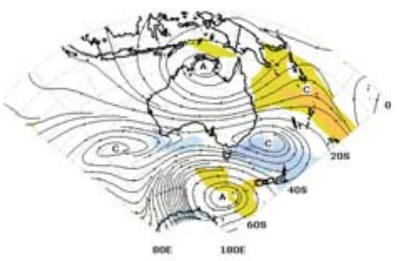

(k)

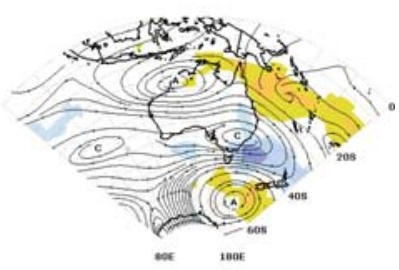

(I)

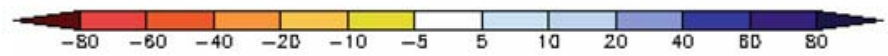

Figure 5

As in Figure 4 but with respect to precipitation rate anomaly fields (shaded, $\mathbf{1 0}^{\mathbf{6}} \mathbf{K g} / \mathbf{m}^{\mathbf{2}} \mathbf{s}^{-\mathbf{1}}$ ) and $200 \mathrm{hPa}$ streamlines of anomalous wind $\left(\mathbf{m s}^{-\mathbf{1}}\right)$. Anomalous fields of precipitation rate are restricted to regions where departures from climatology are statistically significant at the $10 \%$ level.

spring. This is the case of tropical and southeastern Brazil which is affected by dry conditions in summer, and central/southern Brazil, which suffers from wet conditions in spring. These conditions are related to the influence of transient systems which produce anomalous precipitation following the path to the equatorward side of the blocking configuration. The position of the anomalies may be associated with the track of the synoptic systems, which can move northward over the continent in spring, forced by the 
incursion of troughs over Paraguay/southern Brazil, or displaced to the Atlantic Ocean in the summer and do not reach lower latitudes (Fig. 5). The climatic impact of PSE blocking episodes over the South American continent is in good agreement with those obtained by KAYANO et al. (1999).

In the case of the southern Atlantic, blocking episodes have a different impact on temperature and precipitation over South America than those occurring over the Southeastern Pacific. Due to the position of the trough (associated with the blocking dipole) over southern Brazil, Uruguay and central Argentina, these areas are subject to colder than normal conditions at the lower troposphere (Figs. 2 e-h, Figs. 4e-h). However, this is not the case during the summer season, when the trough is located at higher latitudes and the negative temperature anomalies occur only over Argentina. Unlike the Southeastern Pacific cases, the impact of Atlantic blocking episodes on precipitation occurs mainly in the autumn and winter (Figs. 5f, g). This may also be related to the position and intensity of transient systems which develop in the trough region. The wind flow at low levels circumvents the blocking high at lower latitudes in the autumn and winter seasons, forcing the systems to be displaced to lower regions also (Figs. $4 \mathrm{f}, \mathrm{g}$ ).

In the case of Oceania, the impact of blockings episodes on the temperature of Australia is stronger in spring and summer over southern regions, where the trough of the blocking pair is located (Figs. 2i, 1, Figs. 4i, 1). Higher than normal precipitation occurs in extreme southeastern Australia extending to the eastern region while the northern areas may experience drier conditions (Figs. 5i-1).

\section{Case Study: Blocking Episode in the Southern Atlantic}

Despite the relatively low incidence of blocking episodes in the Southern Atlantic sector (Table 2), their impact on the adjacent South American continent may be significant, as shown in Figures 2 to 5. A case study of an intense blocking event appears therefore as specially relevant, and therefore we will present a detailed study on the blocking event that took place between the $4^{\text {th }}$ and the $8^{\text {th }}$ of June 1997 over the South Atlantic Ocean, close to the eastern coast of South America, as shown in Figure 6. The blocking pattern may be observed at high levels, the trough and ridge at $50^{\circ} \mathrm{W}$ being particularly conspicuous (Fig. 6c). The positive geopotential anomaly around $55^{\circ} \mathrm{S}$, as well as the negative one around $30^{\circ} \mathrm{S}$ are also well defined at the $500 \mathrm{hPa}$ (Fig. 6a). The omega-type configuration at low levels (Fig. 6b) and the blocking high at surface (Fig. 6d) are also worthy of notation. Positive precipitation anomalies occur to the east of the upper level trough axes (Fig. 6c) and to the northwest of the blocking high. Due to the persistence of the event, colder than normal temperatures can be seen over parts of southern and southeastern Brazil (Fig. 6b).

Daily zonal averages between $80^{\circ} \mathrm{W}$ and $10^{\circ} \mathrm{E}$ of wind speed at $200 \mathrm{hPa}$ and geopotential height at $500 \mathrm{hPa}$ were also computed in order to analyze the evolution of 


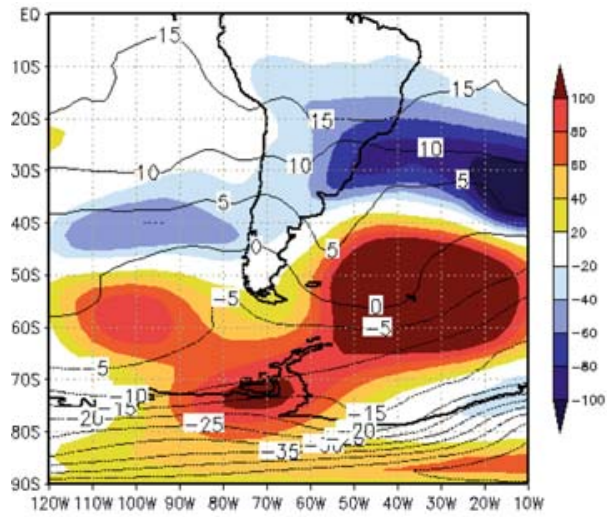

(a)

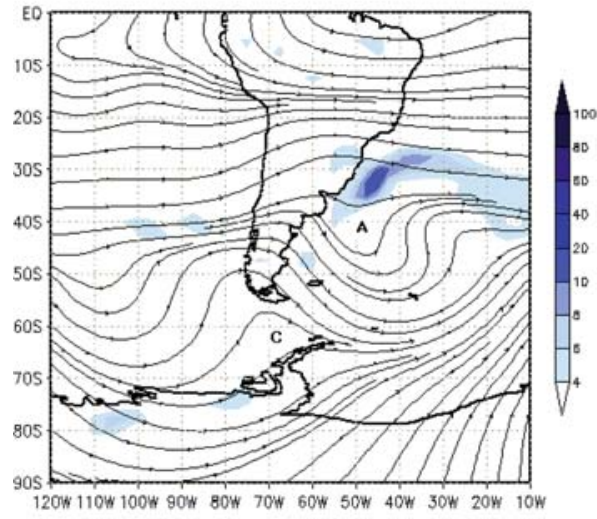

(c)

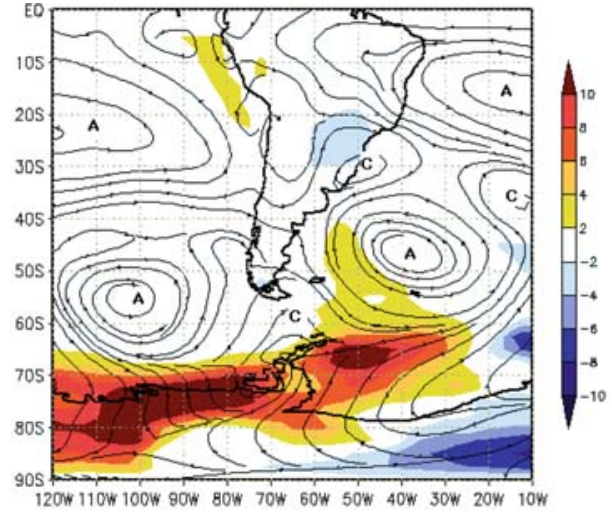

(b)

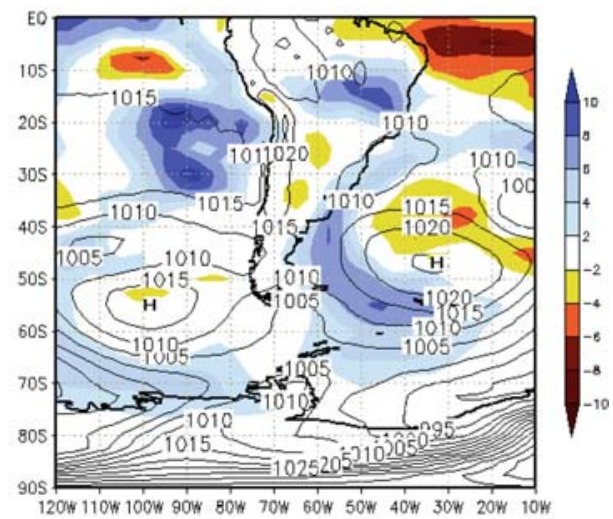

(d)

Figure 6

Composites (a) of $500 \mathrm{hPa}$ anomalous geopotential height (shaded, mgp) and $850 \mathrm{hPa}$ temperatures (contour, ${ }^{\circ} \mathbf{C}$ ), (b) anomalous average temperature (shaded, ${ }^{\circ} \mathbf{C}$ ) and 850 wind (contour, $\mathbf{~ m s}^{-\mathbf{1}}$ ), (c) anomalous precipitation rate (shaded, $\mathbf{1 0}^{\mathbf{6}} \mathbf{K g} / \mathbf{m}^{2} \mathbf{s}^{-\mathbf{1}}$ ) and $200 \mathrm{hPa}$ wind (contour, $\mathbf{m s}^{-\mathbf{1}}$ ), (d) anomalous precipitable water (shaded, $10^{6} \mathbf{~ k g} / \mathbf{m}^{2}$ ) and SLP (contour, mb) for blocking episodes occurring between the $4^{\text {th }}$ and the $8^{\text {th }}$ of June 1997.

this blocking episode. The temporal evolution of selected variables and the corresponding anomalous fields are presented as a function of latitude, in Figures 7 and 8. Two latitudinal bands with intense winds may be observed, associated with the subtropical $\left(25^{\circ} \mathrm{S}\right)$ and polar $\left(75^{\circ} \mathrm{S}\right)$ jets (Fig. $\left.7 \mathrm{a}\right)$, and both jets are more intense than climatology (Fig. 7b). On the contrary, between the $5^{\text {th }}$ and the $7^{\text {th }}$ of June, the large latitudinal band located between the two branches reveals low zonal wind speed, as compared to climatology, particularly around $40^{\circ} \mathrm{S}$ (Fig. 7b). In the case of the $500 \mathrm{hPa}$ geopotential field, the intense anticyclone is particularly well developed between the $4^{\text {th }}$ and the $8^{\text {th }}$ of June (Fig. 8a), with strong positive geopotential height anomalies south of $40^{\circ} \mathrm{S}$ and negative anomalies to the north. Anomalies reaching $300 \mathrm{gpm}$ on the $5^{\text {th }}$ of June around 


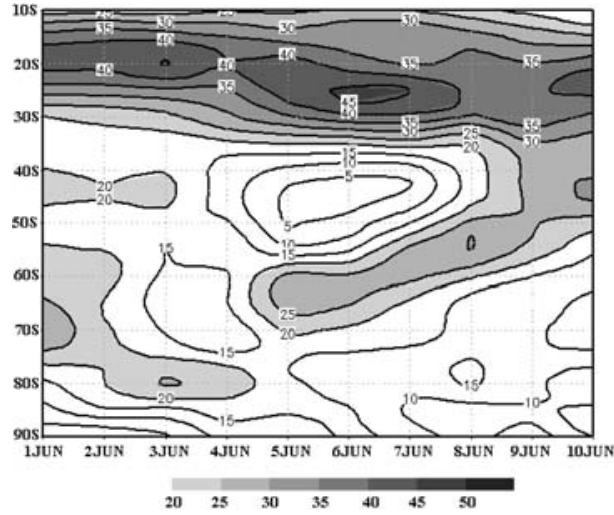

(a)

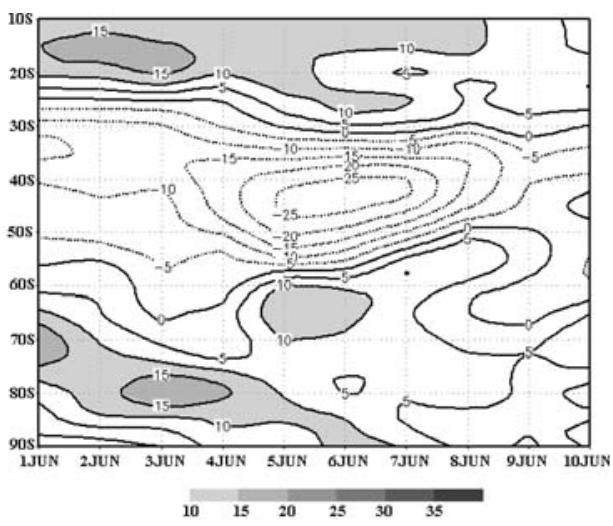

(b)

Figure 7

Daily evolution (between the $1^{\text {st }}$ and the $10^{\text {th }}$ of June 1997) of zonally averaged (between $80^{\circ} \mathrm{W}$ and $10^{\circ} \mathrm{E}$ ) a) $200 \mathrm{hPa}$ wind $\left(\mathbf{m s}^{-\mathbf{1}}\right)$ and b) the corresponding anomalies. Grey is used to highlight regions with values above $20 \mathrm{~ms}^{-1}$ in (a) and above $10 \mathrm{~ms}^{-1}$ in (b).

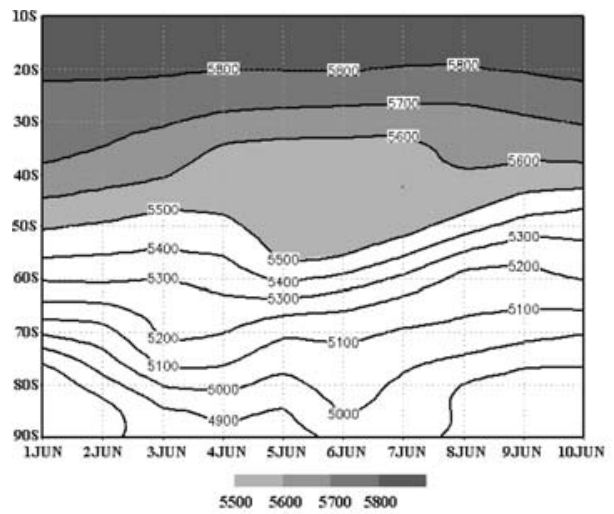

(a)

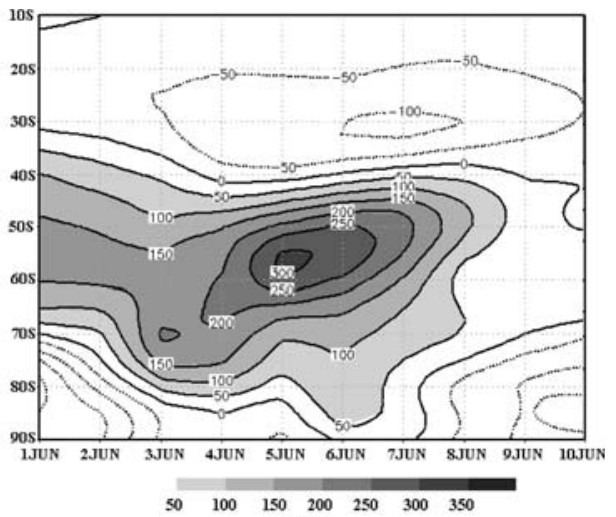

(b)

Figure 8

As in Figure 10, but for $500 \mathrm{hPa}$ geopotential height field (gpm). Grey is used to highlight regions with values above $5500 \mathrm{gpm}$ in (a) and above $50 \mathrm{gpm}$ in (b).

$60^{\circ} \mathrm{S}$ may be observed, indicating the intensity of the analysed blocking episode (Fig. 8b).

A daily sequence of satellite imagery (infrared channel) as obtained at 12.00 GMT from GOES shows the evolution of the low-pressure systems in the vicinity of the intense high pressure sector (Fig. 9). As described in the previous section the low-pressure systems do not cross over the blocking anticyclone, being forced to circumvent the blocking structure and affecting southeastern areas of South America. The associated 

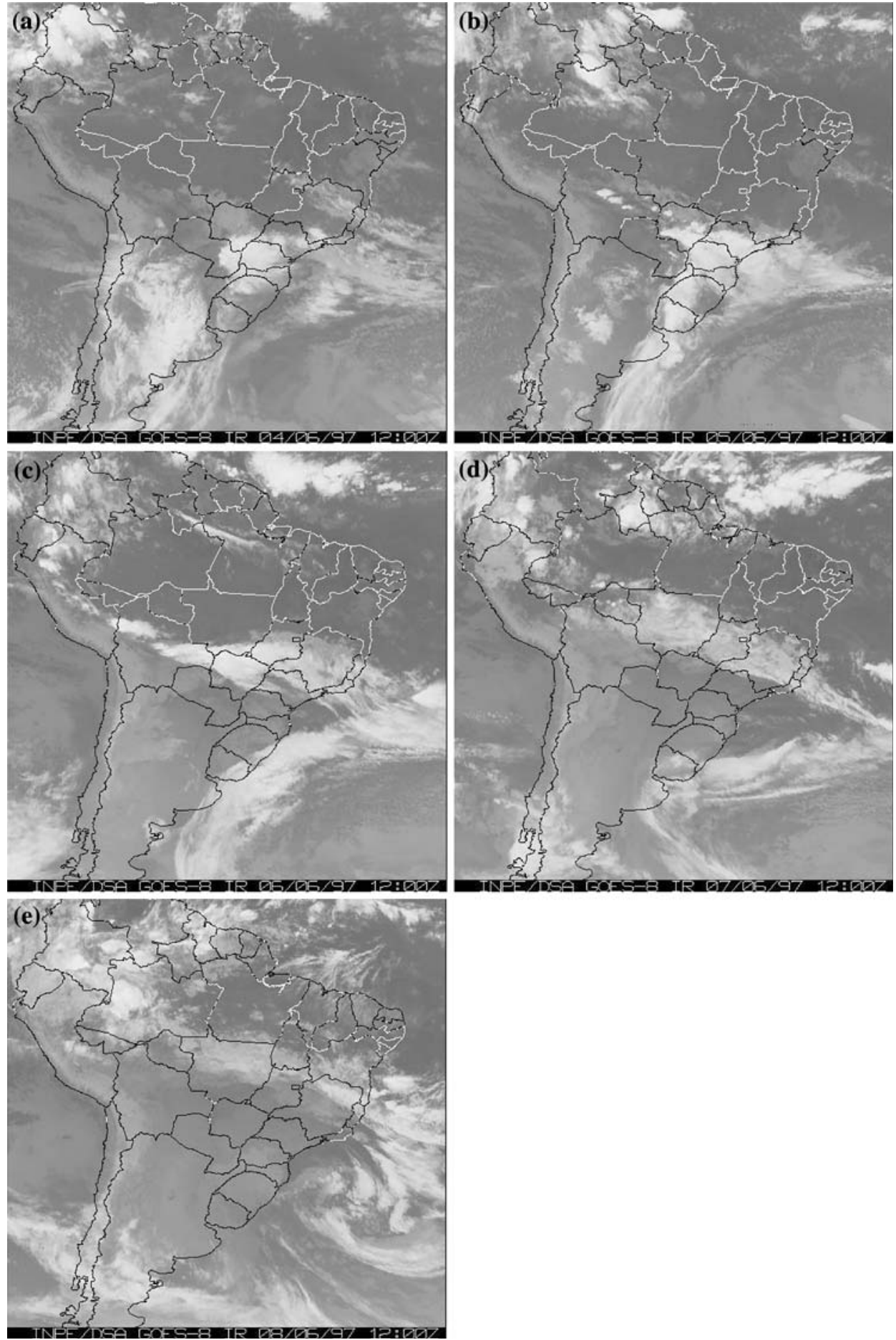
Daily satellite infrared imagery for 4 (a), 5 (b), 6 (c), 7 (d) and 8 (e) of June 1997, as obtained from GOES at $12.00 \mathrm{GMT}$.

convective cloudiness, as seen in the infrared satellite imagery, indicates heavy precipitation in parts of Southern Brazil; a pattern that appears to be quite similar to the one with respect to the average impact of southern Atlantic blocking episodes on precipitation rate (Fig. 5g).

\section{Summary and Concluding Remarks}

Blocking episodes in the SH were found to occur more often over the Southwestern Pacific sector $\left(180^{\circ} \mathrm{W}\right.$ to $\left.120^{\circ} \mathrm{W}\right)$ and over Oceania $\left(100^{\circ} \mathrm{E}\right.$ to $\left.180^{\circ} \mathrm{E}\right)$, in good agreement with the findings by Marques and Rao (2001). Although less frequent than over the Southwestern Pacific, blocking episodes in the Atlantic and Southeastern Pacific sectors have, nevertheless, a significant impact on temperature and precipitation fields over the adjacent continent of South America. In general, blocking episodes present similar anomalous patterns of the analyzed variables over the three considered regions (PSE, ATL, OCN). The climate impact of blocking episodes over the three regions on nearby continents was evaluated and the influences on temperature and precipitation over South America and Australia were assessed. For all the analyzed regions, low-pressure anomalies occurring in the equatorial flank of the blocking pattern have favored the development of the transient systems that may cause precipitation as they move eastwards.

The largest impacts of Southeastern Pacific (South Atlantic) blocking episodes on the mean temperature fields are observed over the south region of South America. Composites of temperature for Southeastern Pacific (Atlantic) blocking episodes show temperatures significantly higher (lower) than the climatological values in southern Brazil, Northern Argentina, Uruguay and Paraguay, and lower (higher) than climatology in the extreme South America region. Accordingly, Southeastern Pacific and Atlantic blocking events affect South America differently. Higher than climatological precipitation occurs over the southeast/central region of South America during Atlantic blocking (winter and autumn seasons). Dry conditions (wet) are found in some areas of southeast and northeastern Brazil (central and southern Brazil) during southeastern Pacific blocking episodes in summer (spring). Blocking events over Oceania affect southeastern Australia with normal to higher than normal precipitation, and the most significant negative temperature anomalies are concentrated in the south and east.

Finally, a case study was performed focusing on the blocking episode that occurred between the $4^{\text {th }}$ and the $8^{\text {th }}$ of June 1997 over the South Atlantic sector. This particularly 
intense event was characterized by the split of the jet stream into two intense and welldefined branches (subtropical and polar) while the band in the intermediate latitudes $\left(35^{\circ} \mathrm{S}-55^{\circ} \mathrm{S}\right)$ was characterized by very low zonal wind speeds. A complementary perspective was provided by satellite imagery that confirmed the presence of transient systems in the periphery of the blocking anticyclone, promoting higher than climatological precipitation in the southeastern sector of South America, namely over Southern Brazil, Uruguay and Northern Argentina.

\section{Acknowledgements}

This work was supported by FCT through project VAST (Variability of Atlantic storms and their impact on land climate) POCTI/CTA/46573/2002, co-financed by the European Union under program FEDER. FCT also supported Monica Damião Mendes through Grants BD/8480/2002 and POCTI/CTA/2002, co-financed by the EU through program FEDER. We thank the NCEP/NCAR (National Centers for Environmental Prediction and National Centers for Atmospheric Research) for providing the reanalysis data. Iracema F. A. Cavalcanti acknowledges CNPq for research support.

\section{REFERENCES}

AdAna, F.J.S. and ColucCI, S.J. (2005), Southern hemisphere blocking onset associated with upper-tropospheric divergence anomalies, J. Atmos. Sci. 62, 1614-1625.

Climanálise (1997) Edição Comemorativa de 10 anos, Instituto Nacional de Pesquisas Espaciais. Cachoeira Paulista, SP. Brasil.

Carrera M.L., Higgins, R.W., and Kousky, V.E. (2004), Downstream weather impacts associated with atmospheric blocking over the Pacific northeast, J. Climate 17, 4823-4839.

Damião, M.C.M., Trigo, R.M., Cavalcanti, F.A.I. and DaCamara, C.C. (2005), Bloqueios atmosféricos de 1960 a 2000 sobre o oceano pacifico sul: impactos climáticos e mecanismos físicos associados, Revista Brasileira de Meteorologia 20, 175-190. (in Portuguese).

Hansen, A.R., PAndolfo, J.P., and Sutera, A. (1993), Midtropospheric flow regimes and persistent wintertime anomalies of surface-layer pressure and temperature, J. Climate 6, 2136-2143.

Kalnay, E., Kanamitsu, M., Kistler, R., Colins, W., Deaven, D., Gandin, L., Iredell, M., Saha, S., White, G., Wollen, J., Zhu, Y., Leetmaa, A., Reynolds, R., Chelliah, M., Ebisuzaki, W., Higgins, W., Janowiak, J., Mo, K.C., Ropelewski, C., Wang, J., Jenne, R., and Joseph, D. (1996), The NCEP/NCAR 40-year reanalyses project, Bull. Am. Meteorol. Soc. 77, 437-471.

Kayano, M.T. and Kousky, V.E. (1990), Southern Hemisphere blocking: A comparison between two indices, Met. Atmos. Phys. 42, 165-170.

Kayano, E. (1999), Southeastern Pacific blocking episodes and their effect on South American Weather, Met. Atmos. Phys. 69, 145-155.

Knox, J. and HAY, J. (1984), Blocking signature in Northern Hemisphere: Rationale and identification, Atmosphere-Ocean 22, 36-47.

LEJENAS, H. (1984), Characteristics of southern hemisphere blocking as determined from a long time series of observational data, Quart. J. Roy. Meteor. Soc. 110, 967-979.

Marques, R.F.C. (1996), Bloqueio Atmosférico no Hemisfério Sul. São José dos Campos, 1996, Ph.D. Thesis. Instituto Nacional de Pesquisas Espaciais. São José dos Campos. Brasil. INPE-6742-TDI/632 (in Portuguese). 
Marques, R.F.C. and RaO, V.B. (1999), A diagnosis of a long-lasting blocking event over the Southeast Pacific Ocean, Mon. Wea. Rev. 127, 1761-1776.

Marques, R.F.C. and RAO, V.B. (2000), Interannual variations of blocking in the Southern Hemisphere and their energetics, J. Geophys. Res. 105, 4625-4636.

Marques, R.F.C. and RAO, V.B. (2001), A comparison of atmospheric blocking over the Southeast and Southwest Pacific Ocean, J. Meteorol. Soc. Japan 79, 863-874.

Montecinos, A. and Aceituno, P. (2003), Seasonality of the ENSO related rainfall variability in central Chile and associated circulation anomalies, J. Climate 16, 281-296.

Pezzi, L.P. and Cavalcanti, I.F.A. (1994), O Jato Subtropical Sobre a América do Sul no Periodo de 1980 a 1989, Anais VIII Cong. Bras Met / II Cong. Lat. Iber. Met. 2, 148-151 (in Portuguese).

RaphaEL, M.N. (2003), Recent, large-scale changes in the extratropical Southern Hemisphere atmospheric circulation, J. Climate 16, 2915-2924.

Rao, V.B., Santos, C.M.E., and Franchito, S.H. (2002), A diagnosis of rainfall over South America during the 1997/98 El Nino event. Part I: Validation of NCEP-NCAR reanalysis rainfall data, J. Climate 15, 502511.

RENWInck, J.A. (1998), ENSO-related variability in the frequency of South Pacific blocking, Mon. Wea. Rev. 126, 3117-3123.

Renwinck, J.A. (2005), Persistent positive anomalies in the Southern Hemisphere circulation, Mon. Wea. Rev. 133, 977-988.

Renwinck, J.A. and Revell, M.J. (1999), Blocking over the South Pacific and Rossby wave propagation, Mon. Wea. Rev. 127, 2233-2247.

Rex, D.F. (1950a), Blocking action in the middle troposphere and its effect upon regional climate. Part I: An aerological study of blocking action, Tellus 2, 196-211.

Rex, D.F. (1950b), Blocking action in the middle troposphere and its effect upon regional climate. Part II: The climatology of blocking action, Tellus 2, 275-301.

ReX, D.F. (1951), The effect of Atlantic blocking action upon European climate, Tellus 3, 1-16.

Ruthland, J. and Fuenzalida, H. (1991), Synoptic aspects of the central Chile rainfall variability associated with the Southern Oscillation, Int. J. Climatol. 11, 63-76.

SiqueiRA, J.R. and Machado, L.A.T. (2004), Influence of the frontal systems on the day-to-day convection variability over South America, J. Climate 17, 1754-1766.

Sinclair, M.R.A. (1996), Climatology of anticyclones and blocking for the Southern Hemisphere, Mon. Wea. Rev. 124, 245-263.

Stendel, M. and Arpe, K. (1997), Evaluation of the hydrological Cycle in Re-Analysis and Observations. ECMWF Re-Analysis Validation Reports - Part 1. ECMWF RE-Analysis Project Report Series 6.

Tibaldi, S. and Molteni, F. (1990), On the operational predictability of blocking, Tellus 42A, 343-365.

Tibaldi, S., Tosi, E., Navarra, A., and Pedulli, L. (1994), Northern and Southern Hemisphere seasonal variability of blocking frequency and predictability, Mon. Wea. Rev. 122, 1971-2003.

TREnBerth, K.E. (1984), Interannual variability of the Southern Hemisphere Circulation, Representative ness of the year of the Global Weather Experiment, Mon. Wea. Rev. 112, 108-123.

Trenberth, K.E. and Mo, K.C. (1985), Blocking in the Southern Hemisphere, Mon. Wea. Rev. 113, 3-21.

TreIDL, R.A., BIRCH, E.C., and SAJECKI, P. (1981), Blocking action in the Northern Hemisphere: A climatological study, Atmosphere-Ocean 19, 1-23.

Trigo, R.M., Osborn, T.J., and Corte-Real, J.M. (2002), The North Atlantic Oscillation influence on Europe: Climate impacts and associated physical mechanisms, Clim. Res. 20, 9-17.

Trigo, R.M., Trigo, I.M., DaCAmara, C.C., and Osborn, T.J. (2004), Winter blocking episodes in the EuropeanAtlantic sector: climate impacts and associated physical mechanisms in the reanalysis, Clim. Dynamics 23, $17-28$.

White, G. (2000), Long-term trends in NCEP/NCAR Reanalysis, Proc $2^{\text {nd }}$ Int Conf on Reanalyes, Reading, United Kingdom. World Meteorological Organization, Geneva Switzerland. WCRP-109 (WMO/TD985), pp. 54-57.

WidMANN, M. and BRETHERTON, C.S. (2000), Validation of mesoscale precipitation in the NCEP reanalysis using a new gridcell data set for the northwestern United States, J. Climate 13, 1936-1950. 
Wiedenmann, J.M., Lupo, A.R., Мокноv, I., and Tiкноnova, E.A. (2002), The climatology of blocking anticyclones for the Northern and Southern Hemisphere block intensity as a diagnostic, J. Climate 15, 34593473.

(Received July 19, 2007, revised June 26, 2008)

To access this journal online:

www.birkhauser.ch/pageoph 